\section{Linfoma primario de testículo}

Sr. Editor:

En el pasado número del mes de marzo de 2004 se publicó en su revista un interesante artículo firmado por los doctores Salvador Osuna et al a propósito del manejo del linfoma primario testicular (LPT) ${ }^{1}$. Ésta es una entidad clínica rara y por lo tanto el establecer criterios definidos en el tratamiento no es una tarea fácil.

En su artículo Salvador Osuna et al describen una serie de 6 pacientes de manera retrospectiva analizando la evolución de dichos enfermos. Dicha evolución difiere de un paciente a otro tal como nos ha demostrado la experiencia en otros trabajos. La afectación particular del sistema nervioso central (SNC) en esta patología es frecuente.

Los autores concluyen que el tratamiento de estos pacientes no está firmemente establecido en el marco de intentar mejorar los resultados en el control de la enfermedad y en la supervivencia global. La conclusión nos parece razonable y estamos globalmente de acuerdo.

En este trabajo se hace una extensa revisión de la literatura pero no se cita una serie publicada por el Rare Cancer Network (RCN) en $2002^{2}$. Esta serie, hasta la fecha de la publicación, era la tercera en número de pacientes. Los pacientes analizados eran 36, de ellos 14 presentaron progresión de la enfermedad, la mayoría en el SNC (8 enfermos). No se observó ninguna recaída en áreas testiculares, ilíacas o paraaórticas si los pacientes habían recibido radioterapia (RT) en esas zonas (mediana de dosis de 31 Gy). En el análisis multivariado se objetivaron como variables independientes a favor de una buena evolución de la enfermedad la edad joven, estadios tempranos del LPT y el tratamiento combinado de RT y quimioterapia.

Nuestra conclusión fue que la RT constituía un aspecto importante en evitar recaídas locorregionales. Es evidente que en un estudio retrospectivo y en patología poco frecuente no se puede aconsejar de manera definitiva una terapéutica específica, pero sí se puede orientar que la RT desempeña un papel definitivo en las recaídas locorregionales en el LPT. Es por ello que en nuestro grupo recomendamos el tratamiento combinado en el LPT.

\section{Bibliografía}

1. Salvador Osuna C, García Zueco J C, Fernández Mosteirín $\mathrm{N}$, et al. Linfoma primitivo de testículo: una terapia sin resolver. Rev Oncol 2004;6:94-8.

2. Zouhair A, Weber D, Belkacemi $Y$, et al: Outcome and patterns of failure in testicular lymphoma: a multicenter rare cancer network study. Int J Radiat Oncol Biol Phys 2002;52:652-6.

Salvador Villà Freixa Oncología Radioterápica. Institut Català d'Odontología. Hospital et de Llobregat. Barcelona. España..

\section{Rotura y migración de catéter de reservorio venoso subcutáneo}

\section{Sr. Editor:}

A propósito del artículo publicado en esta revista "Experiencia clínica con reservorios venosos subcutáneos en pacientes oncológicos" por Cózar Ibánez et al, hemos revisado las complicaciones relacionadas con el empleo de reservorios venosos subcutáneos (RVS) en nuestro centro. La necesidad de efectuar tratamientos por vía venosa central hace que la utilización de RVS se haya convertido en una práctica rutinaria en los pacientes oncológicos. A pesar de ello, dichas técnicas no están libres de complicaciones, algunas de ellas graves, y que en ocasiones pueden deberse a defectos en la técnica de inserción del catéter o del propio reservorio.

La rotura y migración de catéter de RVS es una complicación potencialmente peligrosa, cuya incidencia se estima entre el $0,1 \%$ y el $1 \%$ de los catéteres. La causa principal suele ser la fricción mecánica del catéter venoso central a su paso por el espacio costoclavicular. Una vez roto el catéter, el fragmento distal puede migrar a cavidades cardiacas derechas o arteria pulmonar.

En nuestro centro, se han recogido 4 casos en los últimos dos años, lo que supone una incidencia del 1,7\%. Los pacientes eran dos mujeres de 62 y 63 anos, diagnosticadas de carcinoma ductal infiltrante de mama y de adenocarcinoma de ovario, respectivamente, y dos hombres de 56 y 37 anos ambos diagnosticados de adenocarcinoma de recto. En todos ellos el reservorio fue implantado tras recaída de la enfermedad para iniciar tratamiento con quimioterapia y el acceso se había hecho por vía subclavia derecha.

El tiempo medio desde la inserción del catéter a la fractura fue de 19 meses, aunque existen casos descritos a la tercera semana de la colocación.

En dos de los casos, el diagnóstico fue casual, a través de radiograifías de tórax de control, permaneciendo los pacientes asintomáticos, y en los dos casos restantes, los pacientes presentaban clínica de tos seca o doIor en la región del reservorio.

La localización del catéter migrado fue en la arteria pulmonar izquierda. En tres de ellos la extracción se realizó con éxito mediante catéter-lazo por vía femoral o subclavia derecha, mientras que en uno de los casos los intentos de retirar el catéter fueron infructuosos. A pesar de la imposibilidad de extraer el catéter, el paciente permanece asintomático. Se procedió en todos los pacientes a la implantación de un nuevo RIV sin complicaciones.

Isabel Ruiz Martín, Raquel Salazar Sáez y
Germán Marcos García

Servicio de Oncología Médica. Hospital Clínico Universitario. Salamanca. España 